\title{
Effect of shade on animal welfare, growth performance, and carcass characteristics in large pens of beef cattle fed a beta agonist in a commercial feedlot ${ }^{1}$
}

\author{
J. A. Hagenmaier, * C. D. Reinhardt, $\uparrow$ S. J. Bartle, $\$$ and D. U. Thomson*2 \\ *Department of Diagnostic Medicine/Pathobiology, Kansas State University College of \\ Veterinary Medicine, Manhattan 66506; †Department of Animal Sciences \& Industry, Kansas State University \\ College of Agriculture, Manhattan 66506; and \$Kansas State University Beef Cattle Institute, Manhattan 66506
}

\begin{abstract}
Feedlot cattle $(n=1,395 ; \mathrm{BW}=568 \pm$ $43 \mathrm{~kg}$ ) were used to evaluate the effects of shade on animal welfare, growth performance, and carcass quality during the summer of 2013 in a Kansas commercial feedlot. Seven lots of predominately black steers and heifers (4 and 3, respectively) visually determined to be approaching the final mo on feed were identified, randomly gate-sorted, and allocated to pens located across the feed alley from each other to receive 1 of 2 treatments: 1) Shade (mean shade area $=1.5 \mathrm{~m}^{2} /$ animal) or 2) No shade. Shade was provided using a 13-ounce polyethylene fabric and pens were oriented northwest to southeast. The mean starting date was June 13 and the mean days on feed for lots while on the study was $38 \mathrm{~d}$. Cattle were fed a 77.67\% DM steam-flaked corn-based diet and had ad libitum access to water throughout the duration of the trial. Zilpaterol hydrochloride (ZIL) was included in the finishing ration at an inclusion rate of $8.3 \mathrm{mg} / \mathrm{kg}$ of DM for the last $20 \mathrm{~d}$ on feed with a $3 \mathrm{~d}$ withdrawal period. Pen floor temperatures (PFT) were measured using an infrared thermometer and prevalence of cattle open-mouth breathing (OMB) was recorded on a pen basis. In addition to shade treatment, the effect of
\end{abstract}

temperature humidity index (THI) on PFT and OMB was analyzed by classifying days as either "Alert" (THI $<79$ ) or "Danger" (THI > 79). On the day of slaughter, pens within a replicate were kept separate through all stages of the marketing channel from loading at the feedlot until stunning at the plant. Pen served as the experimental unit for all measurements. There was a $\mathrm{THI} \times$ shade treatment interaction for PFT and OMB $(P<0.001)$ where days classified as "Danger" increased PFT and prevalence of OMB compared to "Alert" days in unshaded but not shaded cattle. Shaded cattle had greater DMI $(P=0.01)$; however, unshaded cattle had greater $\mathrm{G}: \mathrm{F}(P=0.05)$ and therefore no differences were observed in ADG $(P=0.39)$. Shaded cattle had greater dressing percentage $(P=0.01)$, although HCW, LM area, fat thickness, marbling score, and quality grade did not differ between treatments $(P>0.05)$. Heat stress, a significant animal welfare concern and cause of reduced performance in feedlot cattle during the final phase of the feeding period, was alleviated in shaded cattle and illustrates the importance of shade provision as 1 tool to protect the welfare and increase feed consumption in large pens of feedlot cattle during hot summer months.

Key words: beef cattle, growth performance, heat stress, shade, welfare

(C) 2016 American Society of Animal Science. All rights reserved.

J. Anim. Sci. 2016.94:5064-5076 doi:10.2527/jas2016-0935

\section{INTRODUCTION}

In 2015 alone, over 7.2 million commercial cattle were slaughtered during the summer months (USDA,

\footnotetext{
${ }^{1}$ The authors thank Kenny Montgomery, Jerry Bohn, and the rest of the team at Pratt Feeders LLC for their cooperation in conducting this study.

${ }^{2}$ Corresponding author: dthomson@vet.k-state.edu

Received August 23, 2016.

Accepted September 27, 2016.
}

2016). As a result, large numbers of finished cattle are exposed to Midwest summer conditions where heat stress could occur and be potentially devastating with regards to death loss and decreased performance (Hubbard et al., 1999; Mader, 2014). Over a decade ago, St.-Pierre et al. (2003) estimated heat stress in finished beef cattle cost the U.S. approximately $\$ 282$ million, or roughly $1.5 \%$ gross income per animal, annually due to decreased performance and death loss.

Loneragan et al. (2014) reported increased mortality rates in cattle fed the $\beta$-adrenergic agonists 
(BAA) zilpaterol hydrochloride and ractopamine hydrochloride were most prominent in hot summer months. These findings, combined with anecdotal reports of decreased mobility in cattle fed $\beta A A$, have led to scrutiny of $\beta A A$ use and growing welfare concerns in cattle fed $\beta A A$, particularly their ability to cope with heat stress. Samuelson et al. (2016) reports $84.8 \%$ of feedlots consulted by surveyed nutritionists use $\beta$ AA in their finishing cattle. Yet, Samuelson et al. (2016) and Simroth et al. (2016) both report only 17\% of feedlots provide shade in finishing pens. Together, these findings indicate an opportunity for future shade implementation and highlight the need for current research to better appreciate the effects of shade on animal welfare and performance in cattle fed $\beta$ AA.

No studies have evaluated the effect of providing shade under commercial management conditions where entire lots of nearly finished feedlot cattle are staged into shaded pens during summer months and fed $\beta A A$ during final weeks on feed before slaughter. Therefore, the objective of this study was to evaluate the effects of shade provision during hot summer months on the welfare, growth performance and carcass characteristics in large lots of short-fed cattle fed $\beta A A$ at a Kansas commercial feedlot.

\section{MATERIALS AND METHODS}

All animal handling and treatment procedures involved in conducting this study were in compliance with the Guide for the Care and Use of Agricultural Animals in Research and Teaching (FASS, 2010).

\section{Cattle and Experimental Design}

A total of $1,395(\mathrm{BW}=568 \pm 43 \mathrm{~kg})$ predominately black-hided steers and heifers from 7 lots (4 and 3, respectively; mean $=200$ animals) with similar phenotypic characteristics that were visually determined to be approaching the final mo on feed were enrolled in a completely randomized design during the summer of 2013. Animals within a lot had been fed and housed together [mean days on feed $($ DOF $)=89 \mathrm{~d}$ ] in dirt floored pens in accordance with the feedlot's standard operating procedures. Upon arrival and before enrollment on the study, incoming lots of cattle were treated for internal parasites (Synanthic, Boehringer Ingelheim Vetmedica Inc., St. Joseph, MO), external parasites (Noromectin, Norbrook Inc., Lenexa, KS), and vaccinated against clostridial toxins (Ultrabac 7, Zoetis Animal Health, Florham Park, NJ), infectious bovine rhinotracheitis, parainfluenza-3 virus, bovine respiratory syncytial virus, and bovine viral diarrhea virus type I and II (Pyramid 5, Boehringer Ingelheim
Vetmedica Inc.). Lots classified as "high-risk" were identified by the feedlot and received a similar vaccine that incorporated Mannheimia haemolytica toxoid in addition to the viral antigens (Pyramid $5+$ Presponse, Boehringer Ingelheim Vetmedica Inc.). Before study inclusion, all 7 lots received a single steroid implant by 1 of 4 scenarios determined by the feedlot based on arrival weight, degree of finish and projected harvest dates: 1) Revalor 200 (200 mg trenbolone acetate and $20 \mathrm{mg}$ estradiol 17 $\beta$; Merck Animal Health, Desoto, KS) during arrival processing, 2) Revalor 200 approximately $120 \mathrm{~d}$ before slaughter 3 ) Revalor S (120 mg trenbolone acetate and $24 \mathrm{mg}$ estradiol $17 \beta$; Merck Animal Health) during arrival processing, or 4) Revalor S approximately $90 \mathrm{~d}$ before slaughter.

Approximately 1 month before projected slaughter dates, lots of cattle identified for enrollment were independently removed from their home pen and walked to nearby holding pens to be randomly gate-sorted by groups of 5 into 2 smaller groups of similar number (mean $n$ $=100$ animals per group). The resulting smaller groups were then randomly assigned to pens to receive 1 of 2 treatments: 1) Shade or 2) No shade. Pen served as the experimental unit and resulting pairs of pens from a single lot served as a replicate ( $n=7$ replications). The mean study enrollment date, slaughter date, and DOF across replicates were June 13, July 21 , and 38 d, respectively.

\section{Housing and Shade Design}

Pens within a replicate were located directly across the feed alley from each other and oriented northwest to southeast so that feed bunks were located on the southernmost end for shaded pens and vice versa for non-shaded pens. Furthermore, a 5\% slope was maintained from the feed bunk within each pen housing experimental cattle according to the feedlot's standard operating procedures. Shade was provided using a $12.2 \times 13.7 \mathrm{~m}$ structure with 13 ounce polyethylene product (Fig.1; Cattle Cabana, Accu-Steel Inc., Templeton, IA) and structures were positioned along both fence lines so that shade was shared between adjacent pens. A $257 \mathrm{~L}$ water tank (Johnson Concrete Products, Hastings, NE) was positioned within each fence line so that cattle had access to water while under shade, and was in the same location for unshaded pens. The mean shade area, pen space, and linear bunk space over all pens in the study was $1.5 \mathrm{~m}^{2}, 36.2 \mathrm{~m}^{2}$, and $0.55 \mathrm{~m}$ per animal, respectively.

\section{Animal Feeding and Monitoring}

Before enrollment on the experiment, all cattle were fed using the same diet step-up program until maintained on a $77.67 \%$ DM steam flaked corn-based 


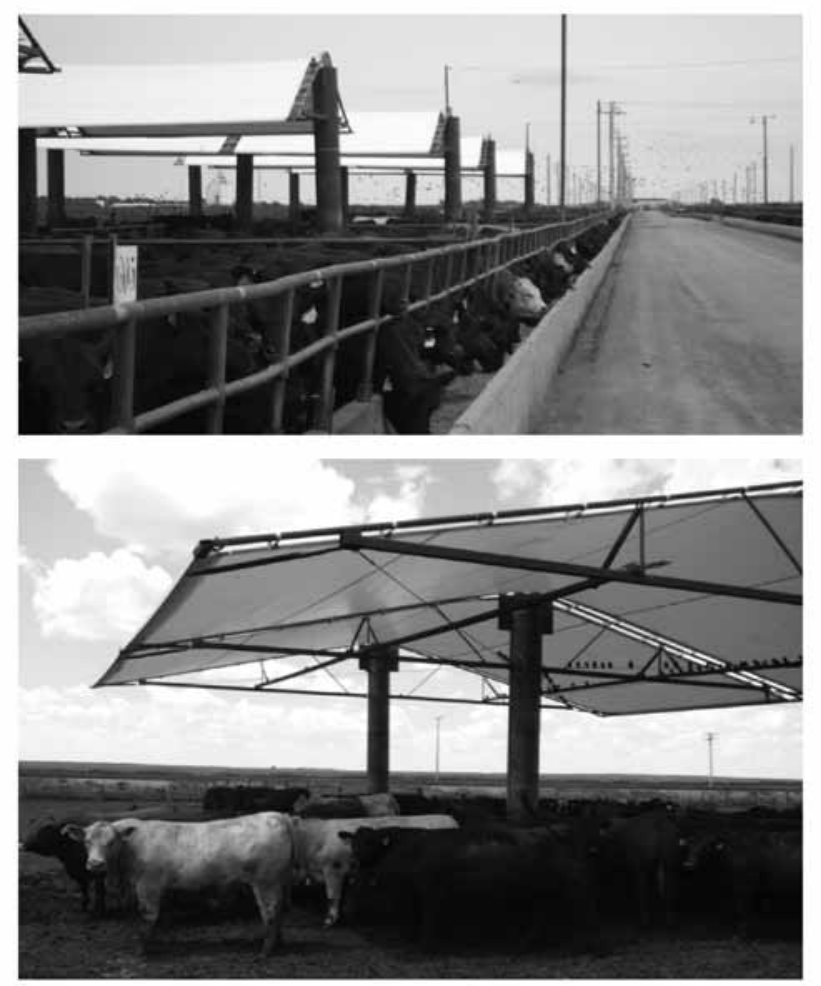

Figure 1. Shade was provided using 13 ounce polyethylene product (Cattle Cabana, Accu-Steel Inc., Templeton, IA) and structures were positioned along both fence lines so that shade was shared between adjacent pens. Water tanks (Johnson Concrete Products, Hastings, NE) were positioned within the fence line so that cattle had access to water while under shade.

finishing diet formulated to meet or exceed the requirements of growing cattle (Table 1; NRC, 2000). Zilpaterol hydrochloride (ZIL; Zilmax, Merck Animal Health) was included in the diet according to label instructions at an inclusion rate of $8.3 \mathrm{mg} / \mathrm{kg}$ DM for 20 $\mathrm{d}$ followed by a $3 \mathrm{~d}$ withdrawal period. Start date of ZIL was determined so that lots met the withdrawal period by the Monday of the week cattle would be shipped for slaughter. In other words, commencement of ZIL administration occurred on a Saturday and the last day cattle received ZIL was on the Thursday 20 d later for all lots. Accordingly, cattle had met the withdrawal period and were eligible for shipment to slaughter the following Monday. Feed bunks were assessed daily beginning at $0500 \mathrm{~h}$ by a trained individual who would estimate orts and consumption to determine the amount of feed to be delivered over 2 daily feedings to provide ad libitum access to feed. Feed deliveries were performed at the same times for shaded and unshaded pens due to their close proximity and to avoid circadian bias. Water was available ad libitum throughout the duration of the study.

Health observations were performed once daily in accordance with the feedlot's standard operating procedures by trained pen riders. Concomitant therapy was under the direction of veterinarians. Only 1
Table 1. Ingredient composition (percent DM basis) and analyzed nutrient content of the finishing diet fed throughout the duration of study period

\begin{tabular}{lc}
\hline \hline Ingredient & $\%$ \\
\hline Steam flaked corn, \% & 52.5 \\
Steam flaked wheat, \% & 24.3 \\
Alfalfa, \% & 8.6 \\
Finish Premix $^{1}, \%$ & 8.1 \\
Liquid Supplement $^{2}, \%$ & 2.8 \\
Tallow, \% & 2.5 \\
Microingredients ${ }^{3}, \%$ & 1.2 \\
\hline Total & 100.0 \\
\hline Analyzed nutrient content, DM basis & \\
\hline DM, \% & 77.67 \\
CP, \% & 16.1 \\
CF, \% & 4.9 \\
aNDF, \% & 13.7 \\
Ca, \% & 0.82 \\
P, \% & 0.37 \\
\hline
\end{tabular}

${ }^{1}$ Formulated to contain (DM basis): $21.4 \%$ sunflower meal, $19.4 \%$ milo dried distillers grains, $17.3 \%$ wheat middlings, $14.5 \%$ ground calcitic limestone $(38 \% \mathrm{Ca}), 11.1 \%$ dolomitic limestone, $4.3 \%$ urea, $3.2 \%$ salt, $2.9 \%$ vitamin/trace mineral supplement (XF Beef \#15, Xtra Factors, Pratt, $\mathrm{KS}), 2.1 \%$ potassium chloride premix $(50 \% \mathrm{~K}), 2.1 \%$ ammonium sulfate, $1.3 \%$ magnesium oxide, $0.20 \%$ zinc sulfate premix $(35.5 \% \mathrm{Zn}), 0.17 \%$ zinc polysaccharide premix $(22 \% \mathrm{Zn}), 0.02 \%$ copper chloride premix $(54 \% \mathrm{Cu})$ and $0.01 \%$ selenium premix $(0.3 \% \mathrm{Se})$.

${ }^{2}$ Formulated to contain $45 \% \mathrm{CP}$ on a $100 \%$ DM basis using $66.9 \%$ corn condensed distillers solubles, $29.2 \%$ cornsteep, and $3.9 \%$ urea.

${ }^{3}$ Formulated to provide each animal a target daily-dose of 50,000 IU vitamin $\mathrm{A}$, vitamin 5,000 IU vitamin $\mathrm{D}_{3}, 50 \mathrm{mg}$ direct-fed microbial (MicroCell Gold, Lallemand Animal Nutrition, Milwaukee, WI), $70 \mathrm{mg}$ zilpaterol hydrochloride (Zilmax, Merck Animal Health, Desoto, KS), 425 mg monensin (Rumensin, Elanco Animal Health, Greenfield, IN), and $90 \mathrm{mg}$ tylosin (Tylan 100, Elanco Animal Health). Additionally, the finishing ration for heifers included melengestrol acetate at a target dosage of $0.50 \mathrm{mg} / \mathrm{animal}$.

animal that received medical treatment failed to meet the established withdrawal time and was therefore unable to be shipped to slaughter with penmates. Postmortem reports were obtained from the feedlot's individual-animal based health management software to calculate the incidence density of mortality.

\section{Heat Stress Observations}

All pens housing experimental cattle were observed and the prevalence of cattle with open-mouth breathing (OMB) was determined between 1500 and 1700 h. Pens within a replicate were observed consecutively to avoid circadian or environmental bias. Open-mouth breathing was defined as the lower jaw being held open exposing the tongue and panting characterized by increased inhalation and exhalation effort (Fig. 2; Johnson et al., 2010). Due to availability of personnel, observations to determine prevalence of OMB was only performed on a subset of days $(n=$ 29). The prevalence of cattle OMB was determined 

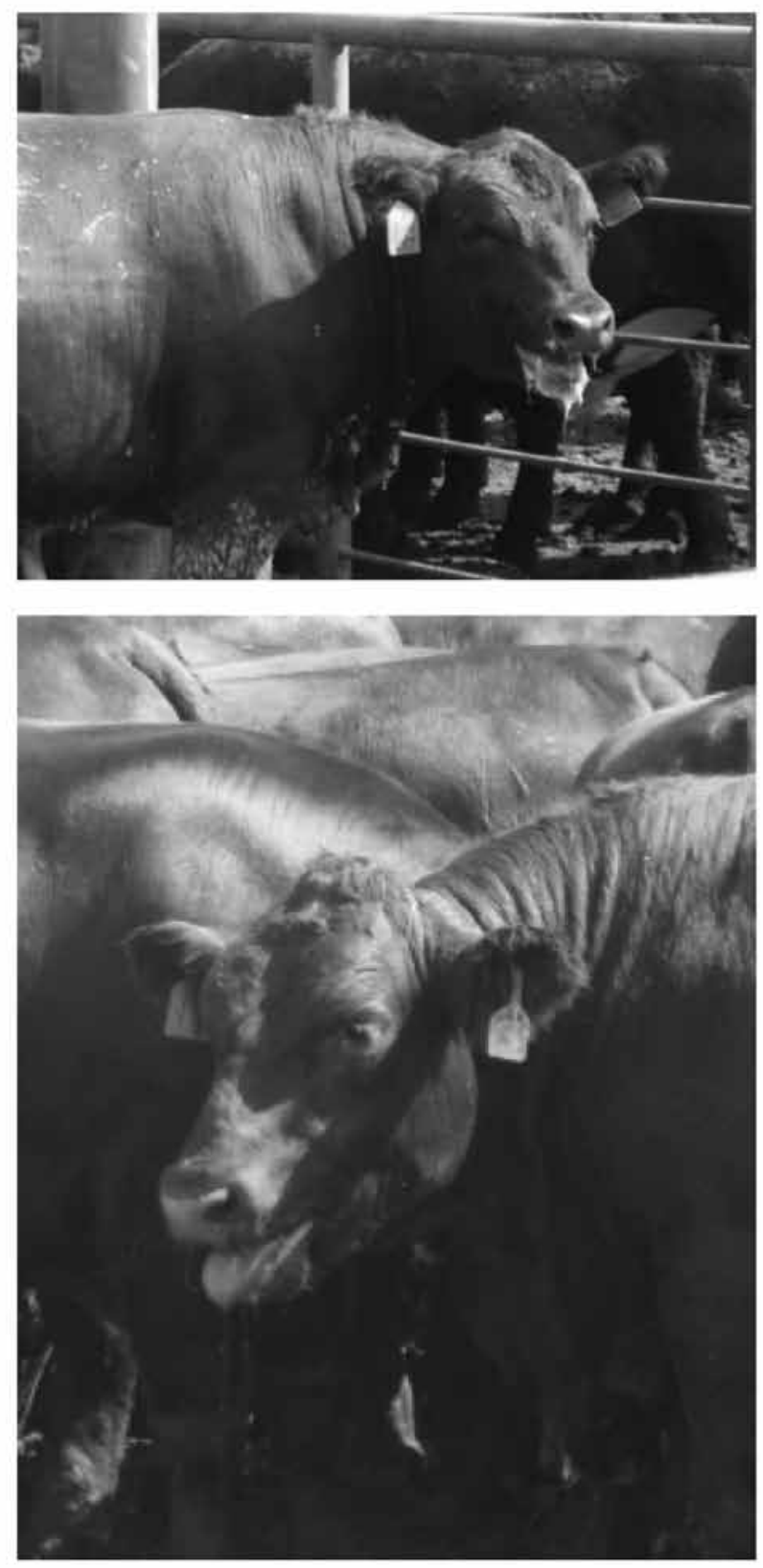

Figure 2. Open-mouth breathing was defined as the lower jaw being held open exposing the tongue and panting characterized by increased inhalation and exhalation effort with flank involvement (Johnson et al., 2010).

by dividing the number of cattle OMB by the total number of cattle in the pen on that day. Immediately after OMB observations for an individual pen housing experimental cattle, pen floor temperatures (PFT) were measured in dirt-floored shaded (shade treatment pens only) and unshaded areas within that pen. Pen floor temperatures were measured on all but $4 \mathrm{OMB}$ observation days $(n=25)$ using a Fluke 62 Mini Infrared Thermometer (Fluke Corporation, Everett, WA). Temperature of unshaded areas was measured in both shaded and unshaded pens to account for variation across pens. However, only temperatures from unshaded pens were used to represent unshaded areas in the statistical analysis because the variation in temperature between pens was less than $1 \%$ of the mean temperature for unshaded pens (data not shown).

\section{Growth Performance and Carcass Characteristics}

Initial and final $\mathrm{BW}$ were obtained using the same certified scale at the feedlot. Initial pen weights for each treatment were obtained during sorting into shaded or unshaded pens and average individual animal weight was calculated by dividing the overall pen weight by the number of cattle in the pen. Final BW was calculated using the same methods during weighout on the mornings cattle were shipped for slaughter. Daily feed deliveries were multiplied by 0.7767 to adjust for DM content and divided by daily pen counts to determine DMI per animal on a pen basis. Then, the mean over the entire study for each respective pen within a replicate was used for analysis.

Data were provided by the abattoir for analysis of carcass characteristics. Quality grades and $\mathrm{HCW}$ were reported for all replicates; whereas LM area, marbling score and 12th rib fat depth were only available for 4 replicates due to differences in marketing strategies in those lots of cattle. Dressing percentages were also reported by the abattoir for all replicates and calculated by dividing the $\mathrm{HCW}$ by the final $\mathrm{BW}$ measured at the feedlot multiplied by 0.96 to account for $4 \%$ shrink.

\section{Weather Data}

Hourly weather data were collected continually throughout the duration of the study at a National Oceanic and Atmospheric Administration (NOAA) weather station located approximately $1.6 \mathrm{~km}$ from the feedlot. The temperature humidity index (THI) was calculated using the same equation as Mader et al. (2006) where THI $=$ $(0.8 \times \mathrm{TA})+[(\mathrm{RH} \times 0.01) \times(\mathrm{TA}-14.4)]+46.4 ; \mathrm{TA}=$ Ambient Temperature; $\mathbf{R H}=$ Relative Humidity. Weather data are summarized over the entire study period and for each replicate independently (Table 2).

\section{Statistical Analysis}

The incidence density for mortality was calculated for each shade treatment using an exact denominator and is reported for incidence of mortalities per 1,000 animal d. For all remaining variables, data were analyzed using the GLIMMIX procedure in version 9.3 of SAS (SAS Inst. Inc., Cary, NC) and pen was considered the experimental unit ( $n=7$ replications). To evaluate the effect of THI, pen-level OMB prevalence and PFT measurements were bucketed into 1 of 2 THI categories 
Table 2. Maximum, minimum, and mean daily ambient temperature (TA), relative humidity $(\mathrm{RH})$ and temperature humidity index (THI) summarized for each replicate and over the entire study period ${ }^{1}$

\begin{tabular}{|c|c|c|c|c|c|c|c|c|}
\hline Item & Rep 1 & Rep 2 & Rep 3 & Rep 4 & Rep 5 & Rep 6 & Rep 7 & Study period \\
\hline \multicolumn{9}{|c|}{ Ambient temperature, ${ }^{\circ} \mathrm{C}$} \\
\hline Maximum & 32.4 & 33.4 & 33.1 & 33.0 & 32.6 & 32.0 & 31.6 & 31.9 \\
\hline Minimum & 18.3 & 19.2 & 19.4 & 19.5 & 19.1 & 19.4 & 19.9 & 19.1 \\
\hline Mean & 25.2 & 26.2 & 26.1 & 26.0 & 25.7 & 25.4 & 25.4 & 25.3 \\
\hline \multicolumn{9}{|c|}{ Relative humidity, $\%$} \\
\hline Maximum & 83.8 & 79.4 & 80.8 & 82.7 & 82.9 & 86.8 & 89.4 & 86.3 \\
\hline Minimum & 29.1 & 26.6 & 28.8 & 29.7 & 30.2 & 34.7 & 40.3 & 35.0 \\
\hline Mean & 55.9 & 51.7 & 54.1 & 55.7 & 55.9 & 60.9 & 78.4 & 60.5 \\
\hline \multicolumn{9}{|c|}{ Temperature humidity index ${ }^{2}$} \\
\hline Maximum & 78.0 & 78.6 & 78.5 & 78.6 & 78.2 & 78.2 & 78.4 & 78.1 \\
\hline Minimum & 64.1 & 65.3 & 65.7 & 66.0 & 65.3 & 66.0 & 66.9 & 65.5 \\
\hline Mean & 71.6 & 72.6 & 72.5 & 72.6 & 72.2 & 72.3 & 72.9 & 72.2 \\
\hline Date Enrolled & June 7 & June 10 & June 10 & June 11 & June 7 & June 14 & July 5 & June 13 \\
\hline Date slaughtered & July 3 & July 11 & July 18 & July 23 & July 22 & August 6 & August 8 & July 21 \\
\hline DOF & 26 & 31 & 38 & 42 & 45 & 53 & 34 & 38 \\
\hline
\end{tabular}

${ }^{1}$ Hourly weather data was collected continually by a weather station located approximately $1.6 \mathrm{~km}$ from the feedlot and accessed through the online National Oceanic and Atmospheric Administration (NOAA) database.

${ }^{2}$ Calculated using the equation from Mader et al. $(2006)$ where $\mathrm{THI}=(0.8 \times \mathrm{TA})+[(\mathrm{RH} \times 0.01) \times(\mathrm{TA}-14.4)]+46.4$.

(THI $_{\text {CAT }}$ ) based on the maximum THI (THI MAX $_{\text {) on }}$ individual observation days. Categories were formed in accordance with the Livestock Weather Safety Index (LWSI) taxonomy for heat stress reported by Mader et al. (2006) so that days with $\mathrm{THI}_{\mathrm{MAX}}>79$ were classified as a "Danger" and days with THI $\mathrm{MAX}<79$ were classified as "Alert". As a result, the model for PFT and OMB included the fixed effects of shade treatment, $\mathrm{THI}_{\mathrm{CAT}}$ and the shade treatment $\times \mathrm{THI}_{\mathrm{CAT}}$ interaction, and replicate was included as a random effect.

Growth performance and carcass data were analyzed with a linear mixed effects model using the GLIMMIX procedure with the fixed effect of shade treatment and a random intercept with replicate identified as the subject to account for the clustering of random effects. Prevalence of cattle USDA grading choice or greater at slaughter were calculated for each pen and used for analysis. In addition to overall growth performance, ADG and G:F were analyzed using a carcass-adjusted final BW calculated by dividing the $\mathrm{HCW}$ by the common dressing percentage of $65.23 \%$ (the mean dressing percentage over all replicates included on the study) to account for possible differences in gut-fill during weigh-out and allow for more accurate evaluation of cattle growth.

The DMI and the change in DMI were evaluated between shade treatments from before initiation of ZIL through d 2 to 9 after commencement of ZIL administration (post-ZIL) using procedures similar to Reinhardt et al. (2014) with day post-ZIL was treated as a repeated measure using an autoregressive covariance structure. Dry matter intake before initiation of
ZIL (baseline) was calculated using the mean DMI for $5 \mathrm{~d}$ before beginning ZIL. One replicate began ZIL after only $1 \mathrm{~d}$ on study; therefore baseline DMI was retrospectively calculated using the consumption before enrollment on study for that replicate.

The effect of sex was not included in the model and will not be discussed in the results section because single sex replicates were used. However, the variation due to sex is accounted by accounting for replicate within the statistical models. Treatment means were estimated using the LSMEANS statement and compared using the PDIFF option in SAS. Statistical differences were determined by $P \leq 0.05$ and tendencies were declared when $0.06 \leq P \leq 0.10$.

\section{RESULTS AND DISCUSSION}

No cattle deaths were deemed to be the direct result from heat stress throughout the duration of the study. When accounting for all mortalities (shaded $=6$; unshaded $=2$ ) that occurred while lots were on study, the incidence density for shaded and unshaded cattle was 0.215 and 0.079 cases per 1,000 animal d, respectively. It is interesting to note that 4 of the 6 mortality cases in shaded cattle occurred in a single lot of heifers and all 4 were diagnosed as atypical interstitial pneumonia (AIP) by a consulting veterinarian. Yet, the unshaded pen representing the same lot had no AIP related deaths. Loneragan et al. (2001) reported that AIP was more likely to occur in heifers, yet the etiology of AIP is poorly understood. Of particular interest in regards to our study, one factor 


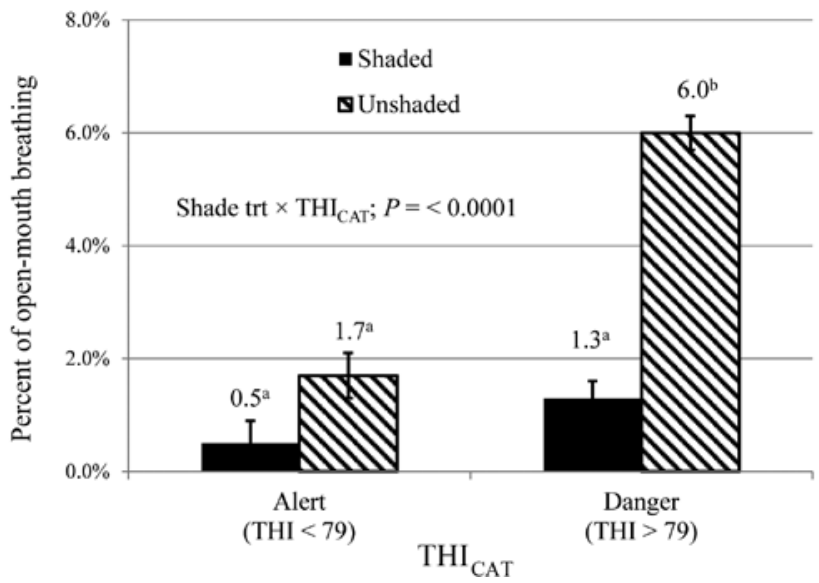

Figure 3. Graphical representation of the pen prevalence of cattle open-mouth breathing (OMB) with access to shade (mean $=1.5 \mathrm{~m}^{2}$ per animal) or no access to shade on days when the temperature humidity index category $\left(\mathrm{THI}_{\mathrm{CAT}}\right)$ were classified as "Alert" $(\mathrm{THI}<79)$ or "Danger" (THI $>79$ ). All pens housing experimental cattle were observed and the number of cattle with open-mouth breathing (OMB) was determined between 1500 and $1700 \mathrm{~h}(n=29 \mathrm{~d})$. There was a shade treatment $\times$ THICAT interaction $(P<0.0001)$. Means without a common lowercase letter $(\mathrm{a}-\mathrm{b}) \operatorname{differ}(P<$ $0.0001)$. The THI was calculated using the same equation as Mader et al. $(2006)$ where $\mathrm{THI}=(0.8 \times \mathrm{TA})+[(\mathrm{RH} \times 0.01) \times(\mathrm{TA}-14.4)]+46.4 ; \mathrm{TA}$ $=$ Ambient Temperature; $\mathrm{RH}=$ Relative Humidity.

suggested to play a role in the AIP pathogenesis is irritation of the airway epithelium secondary to inhalation of dust (Woolums A.R., 2015). To prevent heat stress, which also appears to be related to development of AIP, providing shade seems intuitive for reducing the incidence of this disease. Yet, other possible outcomes associated with providing shade such as cattle crowding into confined areas to compete for shade and associated decreases in ventilation and their effects on AIP frequency have not been extensively studied and merit further consideration.

There was a shade treatment $\times \mathrm{THI}_{\mathrm{CAT}}$ interaction for both PFT and OMB $(P<0.0001)$, whereby days classified as "Danger" increased PFT and prevalence of OMB compared to "Alert" days in unshaded but not shaded cattle (Fig. 3 and 4). Eigenberg et al. (2009) reported polyethylene material effectively reduced predicted heat stress by decreasing solar radiation and ambient temperature. Sullivan et al. (2011) reported similar results where shade reduced panting scores during periods of high heat loads (heat load index $>$ 86) in Angus yearling heifers in Australia; however, panting scores were not decreased by providing shade in periods when the heat load was less significant (heat load index < 86). Likewise, Gaughan et al. (2010) and Blaine and Nsahlai (2011) reported that panting was directly related to thermal loads and decreased by providing shade to feedlot cattle. Furthermore, our findings are in agreement with Valtorta et al. (1997) who measured concrete floor temperatures at a dairy facil-

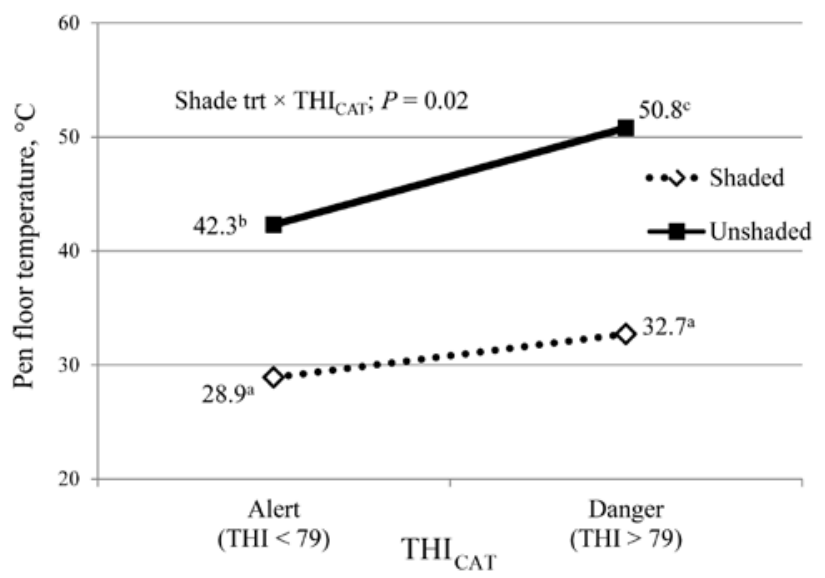

Figure 4. Graphical representation of the interaction between shade treatment and the temperature humidity index category $\left(\mathrm{THI}_{\mathrm{CAT}}\right)$ on pen floor temperatures (PFT) on days when the THI were classified as "Alert" (THI < 79) or "Danger" (THI > 79). Pen floor temperatures were measured using an infrared thermometer on heat all but 4 open-mouth breathing observation days $(n=25)$. Means without a common lowercase letter (a-b) differ $(P<0.05)$. The THI was calculated using the same equation as Mader et al. $(2006)$ where THI $=(0.8 \times \mathrm{TA})+[(\mathrm{RH} \times 0.01) \times(\mathrm{TA}-14.4)]$ $+46.4 ; \mathrm{TA}=$ Ambient Temperature; $\mathrm{RH}=$ Relative Humidity.

ity using an infrared thermometer and reported shade reduced floor temperature by nearly $20^{\circ} \mathrm{C}$.

The heat load cattle experience is dependent on 2 sources: 1) metabolic heat from tissue metabolism and digestive fermentation, and 2) environmental heat (Sullivan et al., 2011; NRC, 2016). Cattle and other species have an effective thermoneutral zone dependent on numerous environmental, animal, and management factors whereby thermoregulation and physiological homeostasis are maintained without necessary adaptation to increase or decrease heat production. However, temperatures above this range in cattle require the animal to expend more energy dissipating heat to thermoregulate through evaporative processes including sweating and respiration (Mader, 2003; NRC, 2016). Heat stress results from a culmination of numerous human, animal, dietary and climatic factors and occurs when the ability to dissipate heat through these evaporative processes becomes overwhelmed by the collective heat load experienced from metabolic and environmental sources (Robertshaw 2006; Sullivan et al., 2011; Gaughan and Mader, 2014). Factors shown to affect the predisposition to heat stress include, but are not limited to, energy content of diets, feeding patterns, phenotypic characteristics, previous history of pneumonia, pen floor design (i.e. availability to access shade, water, and wind), solar radiation, ambient temperature, and relative humidity (Brown-Brandl et al., 2005; Mader et al., 2006; 2010a). Cattle begin open mouth breathing during heat stress to increase tidal volume to more effectively dissipate heat loads that exceed the ability of primary evaporative cooling mechanisms such as sweating, increased respi- 
Table 3. Least squared means for the effects of shade provision on growth performance and carcass characteristics of beef cattle ${ }^{1}$

\begin{tabular}{|c|c|c|c|c|}
\hline \multirow[b]{2}{*}{ Variable } & \multicolumn{2}{|c|}{ Treatment } & \multirow[b]{2}{*}{ SEM } & \multirow[b]{2}{*}{$P$-value ${ }^{2}$} \\
\hline & Shaded & Unshaded & & \\
\hline No. of pens ${ }^{3}$ & 7 & 7 & - & - \\
\hline No. cattle per pen & 100 & 100 & - & - \\
\hline \multicolumn{5}{|l|}{ Growth performance } \\
\hline Initial BW, kg & 570 & 568 & 16.8 & 0.59 \\
\hline Final BW, kg & 644 & 644 & 22.0 & 0.98 \\
\hline DMI, $\mathrm{kg}$ & 10.8 & 10.5 & 0.34 & $<0.01$ \\
\hline ADG, $\mathrm{kg}$ & 1.94 & 1.97 & 0.100 & 0.39 \\
\hline $\mathrm{G}: \mathrm{F}$ & 0.18 & 0.19 & 0.007 & 0.05 \\
\hline \multicolumn{5}{|c|}{ Carcass adjusted growth performance } \\
\hline caFinal BW, $\mathrm{kg}^{4}$ & 645 & 642 & 21.6 & 0.30 \\
\hline $\mathrm{caADG}, \mathrm{kg}^{4}$ & 1.98 & 1.90 & 0.109 & 0.33 \\
\hline $\mathrm{caG}: \mathrm{F}^{4}$ & 0.18 & 0.18 & 0.008 & 0.62 \\
\hline \multicolumn{5}{|l|}{ Carcass characteristics } \\
\hline $\mathrm{HCW}, \mathrm{kg}$ & 404 & 402 & 13.6 & 0.31 \\
\hline Dressing percentage $\mathrm{e}^{5}$ & 65.41 & 65.05 & 0.002 & 0.01 \\
\hline $\mathrm{LM}$ area, $\mathrm{cm}^{2,6,7}$ & 95.5 & 93.2 & 2.37 & 0.13 \\
\hline 12th rib fat depth, $\mathrm{cm}^{6,8}$ & 1.38 & 1.34 & 0.093 & 0.34 \\
\hline Marbling score 6,9 & 441 & 433 & 12.2 & 0.36 \\
\hline Choice or greater, $\%$ & 72.3 & 67.0 & 0.02 & 0.12 \\
\hline
\end{tabular}

${ }^{1}$ Large lots of predominately black steers or heifers (4 and 3, respectively) visually determined to be approaching the final month on feed were identified and randomly gate-sorted and allocated to pens located across the feed alley from each other to receive 1 of 2 treatments: 1 ) Shaded or 2) Unshaded

${ }^{2}$ Statistical significance was declared for $P \leq 0.05$ and tendencies were declared when $0.06 \leq P \leq 0.10$.

${ }^{3}$ Pen was considered the experimental unit.

${ }^{4}$ Growth performance estimates were based on a carcass-adjusted final BW using a common dressing percentage of $65.23 \%$ to remove potential differences in gut fill and allow for more accurate evaluation of growth.

${ }^{5}$ Final BW was adjusted for $4 \%$ shrinkage before calculation and statistical analysis of dressing percentage.

${ }^{6}$ Data were analyzed on only 4 lots, these variables were not reported for the remaining lots $(n=3)$ due to differences in marketing strategies.

${ }^{7}$ Measured between the 12 th and 13 th ribs.

${ }^{8}$ Measured over the 12 th rib.

${ }^{9}$ Evaluated in the longissimus dorsi $\mathrm{m}$. between the 12th and 13th ribs; Traces $=200$, Slight $=300$, Small $=400$, Modest $=500$, Moderate $=600$, Slightly Abundant $=700$.

ratory rate, or "through the nose" panting (Robertshaw, 2006; Sullivan et al., 2011; Gaughan and Mader, 2014). It has been proposed a slight increase in respiration rate and effort or both can increase maintenance energy expenditure by $7 \%$ and in cases of severe, labored, openmouth breathing the maintenance requirement can be increased by 11 to $25 \%$ (NRC, 1981).

The effect of shade on growth performance and carcass characteristics in feedlot cattle has been studied extensively; however, the outcomes reported are inconsistent. In the current study, shaded cattle had greater DMI $(P<0.01$, Table 3$)$; however, unshaded cattle had greater G:F $(P=0.05)$ and as a result ADG and final BW did not differ between treatments $(P>0.05)$. On the other hand, and similar to ADG, G:F did not differ between treatments $(P>0.05)$ when analyzing growth performance using a carcass adjusted final BW. In similar climatic conditions as those experienced by the cattle on the current study, Mitlöhner et al. (2001, 2002) reported increased feed consumption in Bos taurus feedlot cattle provided shade in the Texas panhandle. However, those studies also reported improved ADG reflecting the increase in DMI in shaded cattle, which differs from the current study. Conversely, Boyd et al. (2015) reported DMI in feedlot cattle is unaffected by shade in Nebraska with environmental conditions similar to the current study. Similarly, Bond and Laster (1975) also reported shade had no effect on DMI in bulls fed high-roughage diets in Nebraska. Others have speculated shade did not benefit growth performance of cattle in certain situations due to an ability to acclimate to heat and compensate so effectively where the benefits of shade provision are diminished (Mader et al., 1999a; Brown-Brandl et al., 2006). For instance, Mader et al. (1999a) speculated compensatory responses to heat could explain their findings in Angus $\times$ Hereford crossbred cattle fed in pens with wind barriers where feed conversion was improved during 0 through 56 DOF in shaded compared to unshaded cattle; yet, the opposite was true during the last $22 \mathrm{DOF}$ as unshaded cattle tended to have greater G:F.

Relative to the large amount of research conducted to evaluate the effect of shade in feedlot cattle, only a small number of studies have included cattle fed $\beta A A$. From the research reported, Boyd et al. (2015) concluded shade did not improve growth performance in cattle fed ZIL for $21 \mathrm{~d}$ in Nebraska, whereas Barajas et al. (2009) reported shade increased ADG by $8.8 \%$ and improved G:F by $6.1 \%$ in cattle fed ZIL for $30 \mathrm{~d}$ at the end of a 248 $\mathrm{d}$ trial in northwest Mexico. In a study where ZIL was fed to predominantly Bonsmara crossbred steers and bulls in South Africa for $35 \mathrm{~d}$, Blaine and Nsahlai (2011) found shade increased ADG, and although measured at the pen level and therefore not statistically analyzed, DMI was roughly $0.2 \mathrm{~kg} /$ animal more per $\mathrm{d}$ for shaded animals and G:F was improved by $7.2 \%$.

It is well-accepted that greater heat loads lead to decreased DMI (Hahn, 1999), and the fluctuations in DMI and $\mathrm{THI}_{\mathrm{MAX}}$ appear to be closely related on the current study (Fig. 5). Peaks in $\mathrm{THI}_{\mathrm{MAX}}$ are followed by decreases in DMI (Fig. 5) for both shaded and unshaded cattle, suggesting DMI does not decrease on the $d$ of the heat event, but rather on the subsequent $d$ due to carry-over heat loads. This is expected, as feed delivery would have been completed and a majority of feeding time occurs before the heat of the $\mathrm{d}$ in commercial feedlots. Furthermore, others have suggested decreased 


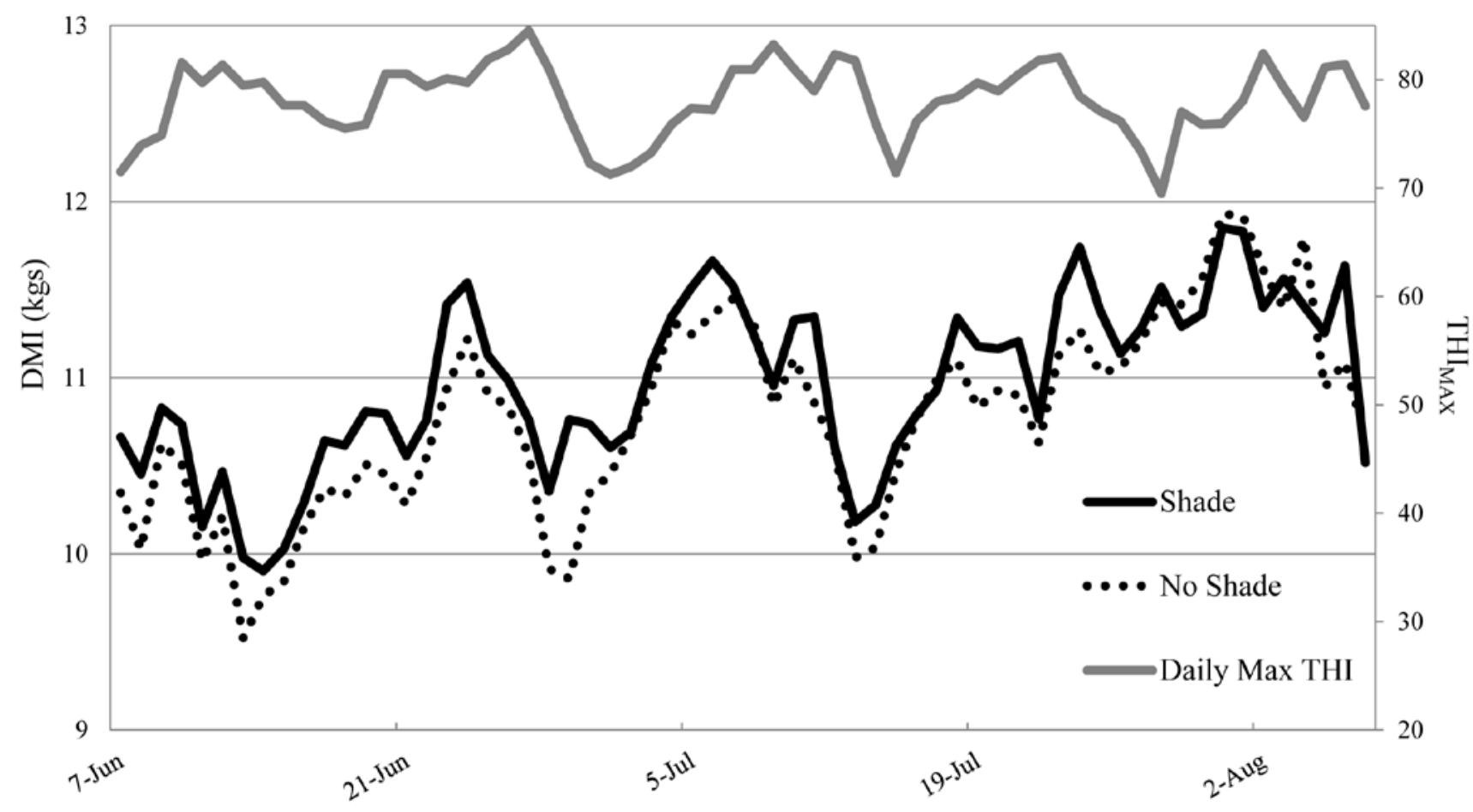

Date

Figure 5. Graphical representation of mean daily DMI for shaded vs. unshaded pens and maximum temperature humidity index (THI $\mathrm{MAX}$ ) throughout the entire study period. Daily DMI was calculated by taking the mean DMI across all pens on each shade treatment at that time. The THI was calculated using the same equation as Mader et al. $(2006)$ where $\mathrm{THI}=(0.8 \times \mathrm{TA})+[(\mathrm{RH} \times 0.01) \times(\mathrm{TA}-14.4)]+46.4 ; \mathrm{TA}=$ Ambient Temperature; $\mathrm{RH}=\mathrm{Relative} \mathrm{Humidity}$.

DMI on d subsequent to heat stress indicates failure of cattle to adequately dissipate heat overnight when THI remains high (Mader et al., 2006; Gaughan et al., 2008). A minimum nightly THI value greater than 70 has been proposed to be a strong indicator that cattle were not able to effectively cool down overnight and could be indicative of inadequate heat abatement achieved overnight to reduce or prevent heat stress the following $\mathrm{d}$ (Mader et al., 1999a, 2006, 2010b). When adequate heat abatement fails to occur overnight, cattle continue to pant to utilize cooler morning temperatures and increased body to environment temperature gradients to dissipate residual heat from the previous d (Brosh et al., 1998; Gaughan and Mader, 2014). Gaughan and Mader (2014) proposed panting within 1 to $2 \mathrm{~h}$ from sunrise is likely due to the animal trying to recover and compensate from heat experienced the previous d. Mader and Kreikemeier (2006) reported heat stressed cattle may prepare for impending heat loads by overcompensating and reducing body temperatures further than expected during the morning. Collectively, findings from previous research combined with the DMI fluctuations observed in concert with changes in THI on the current study further support the use of tools such as THI and the Heat Load Index (Gaughan et al., 2008) to predict heat periods of heat stress.

Reinhardt et al. (2014) analyzed feed intakes from more than 1,500 pens from 3 different commercial
Kansas feedlots and reported reduced DMI shortly after initiation of ZIL administration, especially during summer months. The findings of the current study support this, as DMI was lower and the decrease in DMI was greater in unshaded compared to shaded cattle when pooled across d 2 through $9(P<0.01$; Fig. 6 and 7), although the shade treatment $\times$ post-ZIL day interaction was not significant $(P>0.05)$. Certainly, limitations of the current study are low number of replications and the inability to extend baseline DMI calculations over a longer period to account for possible trends in DMI before ZIL initiation. Still, our findings suggest shade mitigated the decrease in DMI after ZIL administration, which warrants further discussion. Although the exact mechanism for the decrease in DMI after commencement of ZIL is not completely understood, Reinhardt et al. (2014) proposed BAAinduced metabolic alterations leading to increased glycogenolysis and lactate production, hepatic preference of propionate from grain-fed diets as the substrate for gluconeogenesis, and consequent build-up of lactate concentrations resulting in secondary intake depression as one possible cause. Moreover, the original Zilmax label called for inclusion based on $\mathrm{g} / \mathrm{ton}$ only, resulting in DMI as the lone determinant of actual amount of ZIL consumed. Given this fact, it is foreseeable that doses of ZIL greater than approved 


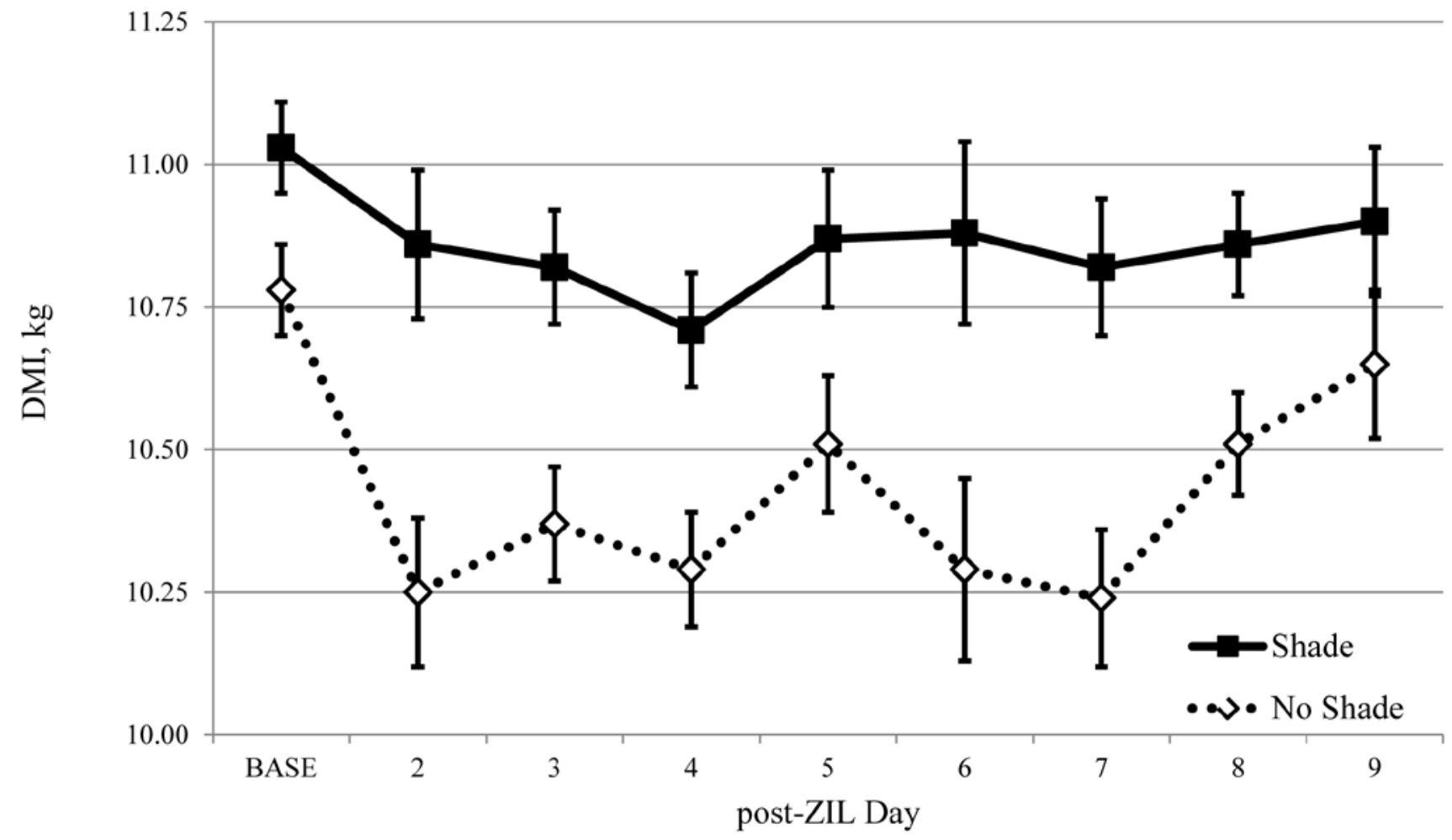

Figure 6. Mean daily DMI after initiation of zilpaterol hydrochloride (ZIL) administration by day of zilpaterol feeding (post-ZIL day) and shade treatment (based on Reinhardt et al., 2014). Shaded cattle had greater $(P=0.01)$ pooled mean DMI over d $2-9$ after initiation of ZIL administration, however the shade $\times$ day interaction was insignificant $(P=0.38)$. Baseline DMI (BASE) was determined by calculating the mean DMI for the $5 \mathrm{~d}$ before the initiation of ZIL administration.

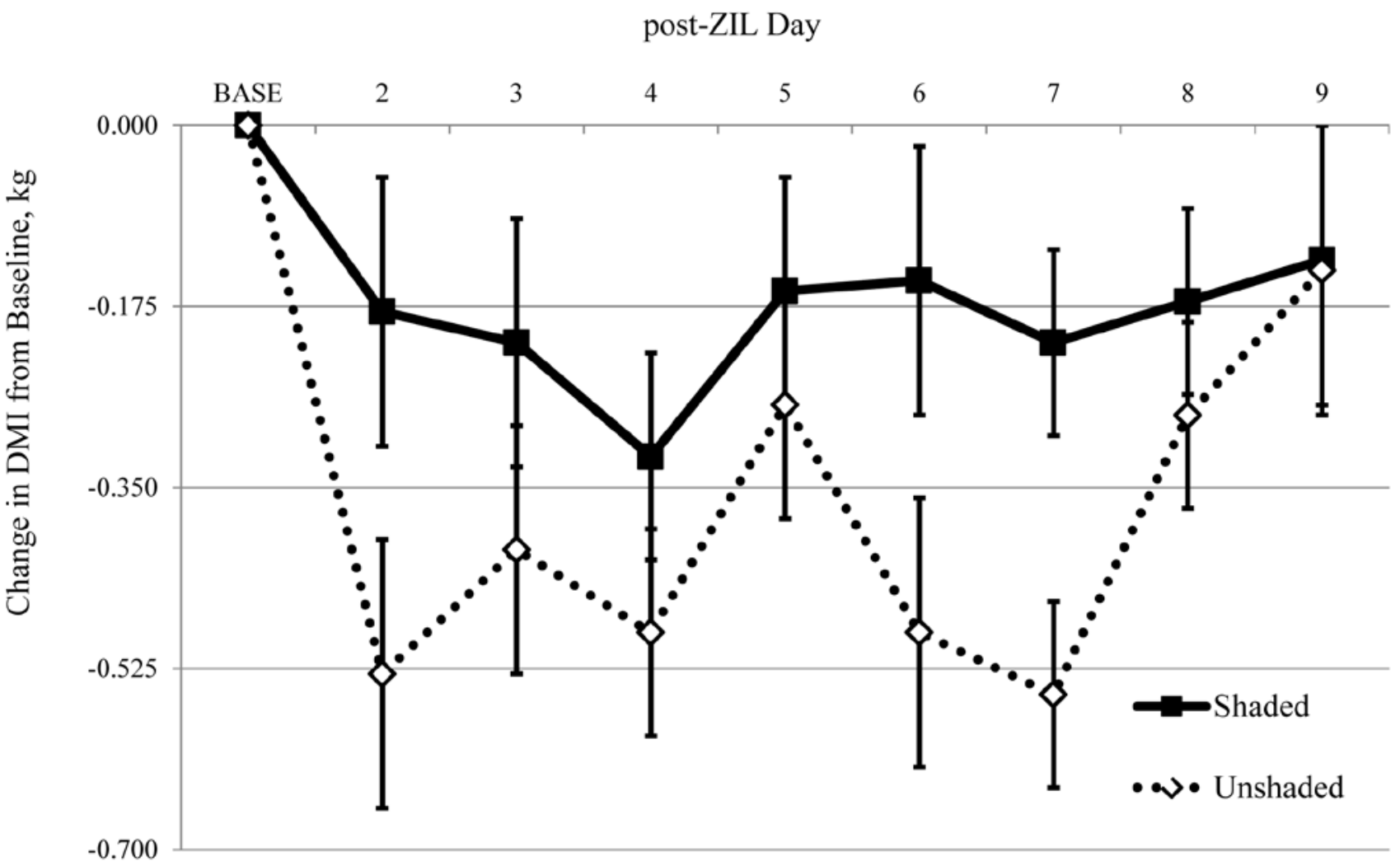

Figure 7. Mean change in daily DMI from baseline after initiation of zilpaterol hydrochloride (ZIL) administration by day of zilpaterol feeding and shade treatment (based on Reinhardt et al., 2014). Shaded cattle had smaller $(P=0.01)$ pooled decreases in DMI over d $2-9$ after initiation of ZIL administration, however the shade $\times$ day interaction on the decrease in DMI was insignificant $(P=0.95)$. Baseline DMI (BASE) was determined by calculating the mean DMI for the $5 \mathrm{~d}$ before the initiation of ZIL administration. 
ranges occur in subsets of cattle and decreased DMI after initiation of ZIL could manifest as a dose-dependent side effect not observed in pre-approval research (Reinhardt et al., 2014; Frese, 2015).

The growth performance advantages achieved through use of $\beta$ AA such as ZIL appear to be achieved through decreased protein degradation and increased protein accretion (Mersmann, 1998; Quinn et al., 2008; Strydom et al., 2009). Increased protein accretion results in increased metabolic heat production (Chwalibog et al., 1996). Therefore, it is conceivable such increases in metabolic heat predispose certain cattle to heat stress. To cope with added heat loads, Taylor et al. (1969) and Beatty et al. (2006) reported cattle increase respiratory rates and hyperventilate, resulting in respiratory alkalosis. Bruckmaier and Blum (1992) reported a more potent $\beta A A$ (clenbuterol) increased lactate and glucose concentrations immediately after administration and speculate skeletal muscle glycogenolysis appears to be mediated by $\beta$-adrenoreceptors. Because of this, Reinhardt et al. (2014) speculated that if ZIL has similar effects as clenbuterol thereby increasing lactate production, simultaneous commencement of ZIL administration with heat stress could amplify the degree of respiratory alkalosis cattle endure and present as voluntary reductions in feed consumption.

Shaded cattle had greater dressing percentages $(P=0.01$, Table 3$)$; otherwise there were no effects of shade treatment for the remaining carcass characteristics $(P>0.05)$. Similar to growth performance, the benefits of shade on carcass traits reported in the literature are varying. Barajas et al. (2009) reported $3.6 \mathrm{~m}^{2}$ shade increased dressing percentage by 3 -fold times greater than it did on our study and also led to increased $\mathrm{HCW}$, although the cattle in that study were mixed Bos taurus and Bos indicus bull calves and the duration of shade provision on their study was almost 8 -fold longer. Blaine and Nsahlai (2011) reported that providing $2.9 \mathrm{~m}^{2}$ shade increased HCW by around 9 $\mathrm{kg}$ over a $35 \mathrm{~d}$ ZIL feeding period. Mitlöhner et al. (2001) reported shade increased HCW and fat thickness in Charolais heifers. Our findings differ from Boyd et al. (2015) who reported shade did not improve dressing percentage in cattle fed ZIL for $21 \mathrm{~d}$ or not fed a $\beta A A$, although our findings are in agreement as shade also did not increase HCW, LM area, fat thickness, or marbling scores on their study. Mader et al. (1999a) reported shade had no effect on dressing percentage, fat thickness and marbling score in Angus $\times$ Hereford crossbred steers provided $2.65 \mathrm{~m}^{2}$ shade area compared to unshaded cattle. Furthermore, our findings support several studies where shade provision did not improve carcass quality grades of beef cattle
(Mitlöhner et al., 2001; Gaughan et al., 2010; Boyd et al., 2015). Mitlöhner et al. (2002) reported shade increased the percent of Angus cross and Charolais cattle grading USDA Choice, although marbling score did not differ and therefore they report the difference was attributed to a reduced prevalence of dark cutting carcasses. There were only 2 dark cutting carcasses on the current study and both were shaded cattle from a single lot. One could reason that some dark-cutting carcasses may be associated with chronic heat stress leading to depletion of muscle glycogen, as glycogen is the main determinate of post-mortem decreases in carcass $\mathrm{pH}$ and prevention of dark-cutting carcasses (Scanga et al., 1997), although these findings have not been reported consistently in the literature.

More research is needed which evaluates the ideal amount of shade required by feedlot cattle to improve performance in a cost-effective manner for modern feedlots. The amount of shade space provided in our study (1.5 $\mathrm{m}^{2}$ /animal) was considerably less than other studies (Mader et al., 1999a; Sullivan et al., 2011). Early research conducted in beef cattle in California suggested an adequate shade area per animal around $5.5 \mathrm{~m}^{2}$ (Bond et al., 1958), however this is not practical given modern feedlot pen designs and stocking densities. Garrett et al. (1962) found that providing 4.6 vs. $2.5 \mathrm{~m}^{2}$ did not improve growth performance in Hereford steers in California. Likewise, Sullivan et al. (2011) evaluated the effects of different available shade space $\left(2.0,3.3\right.$, and $4.7 \mathrm{~m}^{2}$ /animal) in shortfed cattle similar to the lots on our study and found that providing more than $2.0 \mathrm{~m}^{2}$ does not offer added growth performance advantages, although panting scores were improved with greater shade availability. More recently, Boyd et al. (2015) found no advantages in growth performance or carcass characteristics when cattle fed ZIL were provided $3.0 \mathrm{~m}^{2}$ of shade. According to a recent survey conducted by Simroth et al. (2016), only 7 of 42 (17\%) feedlots provided shade. Furthermore, only 1 feedlot provided more than 2.3 $\mathrm{m}^{2}$ shade area per animal. Based on our field experiences and the findings of Simroth et al. (2016), the scenario presented in the current study where cattle were provided $1.5 \mathrm{~m}^{2}$ shade area is typical of situations feedlot managers face in regards to decision-making with large lots of heavy cattle prone to heat stress and a limited number of pens with shade due to the cost of implementation. As a result, feedlot managers may be inclined to stage lots in a manner that maximizes number of animals with availability to shade as long as bunk space and pen size are adequate.

Cattle fed diets with greater energy concentrations to maximize gain in feedlot settings generate greater amounts of metabolic heat compared to lower-energy, 
Table 4. Five year perspective of the mean daily-high for ambient temperature (AT) and temperature humidity index (THI) during the summer months at the feedlot used in the current study and the Livestock Weather Safety Index heat stress classifications based on THI ${ }^{1}$

\begin{tabular}{|c|c|c|c|c|c|}
\hline Item & 2011 & 2012 & 2013 & 2014 & 2015 \\
\hline \multicolumn{6}{|c|}{ Ambient Temp., ${ }^{\circ} \mathrm{C}$} \\
\hline June & 34.9 & 32.8 & 31.2 & 29.2 & 31.1 \\
\hline July & 38.6 & 37.1 & 31.7 & 29.5 & 33.0 \\
\hline August & 35.6 & 32.2 & 30.5 & 33.1 & 30.7 \\
\hline \multicolumn{6}{|l|}{$\mathrm{THI}^{1}$} \\
\hline June & 79.4 & 77.9 & 77.0 & 72.5 & 74.0 \\
\hline July & 82.4 & 81.0 & 77.8 & 72.3 & 75.0 \\
\hline August & 80.8 & 76.9 & 77.7 & 75.7 & 72.8 \\
\hline Code & & \multicolumn{4}{|c|}{ THI } \\
\hline Normal & & & \multicolumn{3}{|c|}{$\mathrm{THI} \leq 74$} \\
\hline Alert & & & \multicolumn{3}{|c|}{$74<$ THI $<79$} \\
\hline Danger & & & \multicolumn{3}{|c|}{$79 \leq \mathrm{THI}<84$} \\
\hline Emergency & & & \multicolumn{3}{|c|}{$84 \leq \mathrm{THI}$} \\
\hline
\end{tabular}

${ }^{1}$ Data was obtained using a weather station located approximately 1.6 $\mathrm{km}$ from the feedlot and accessed through the online National Oceanic and Atmospheric Administration (NOAA) database. Temperature humidity index was calculated using the same equation as Mader et al. (2006) where $\mathrm{THI}=(0.8 \times \mathrm{TA})+[(\mathrm{RH} \times 0.01) \times(\mathrm{TA}-14.4)]+46.4 ; \mathrm{TA}=$ Ambient Temperature; $\mathrm{RH}=$ Relative Humidity.

roughage-based diets in other phases of the beef production systems and are therefore at greater risk to be adversely affected by heat stress (Mader et al. 1999b). In addition to dietary contributions to heat load, a majority of feedlot cattle harvested have black hides (McKeith et al., 2012; Corah, 2016) and are raised in arid environments without the ability to access to naturally occurring shade or bodies of water to help dissipate heat. Indeed, the decision for feedlot managers of whether or not to invest in shade structures is dependent upon many factors, particularly recent heat loads and associated death and performance losses. Furthermore, the time required to achieve breakeven on the cost of constructing shades is difficult to predict as weather conditions and the net benefits from shade will likely vary greatly from year to year. For instance, the feedlot described herein may have observed more profound advantages in cattle performance and positive returns on investment during 2011 where the mean daily-high THI was greater than 79 for each of the summer months (Table 4), whereas none of the months had a mean daily-high THI greater than 79 during 2013 while the current study was being conducted (data obtained from the National Oceanic and Atmospheric Administration online database).

In conclusion, the findings of this study indicate shade decreased the prevalence of open-mouth breathing suggesting that heat stress was visually alleviated. Additionally, provision of shade increased feed con- sumption, the ultimate driver of feedlot performance, but did not lead to increased gains during the mild summer of 2013. Together, these findings advocate shade as an effective tool to protect the welfare of beef cattle at feedlots and suggest even short-term access to shade may offer performance advantages in large lots of cattle during hot summer conditions at the end of the feeding period.

\section{LITERATURE CITED}

Barajas, R., B. J. Cervantes, M. A. Espino, F. Juarez, J. A. Romo, and E. A. Velazquez. 2009. Influence of pen-shade on feedlot performance and carcass characteristics of bulls naturally exposed long time to high temperature In: Proceedings. Vol. 60. Western Section of ASAS, p. 112-115.

Beatty, D. T., A. Barnes, E. Taylor, D. Pethick, M. McCarthy, and S. K. Maloney. 2006. Physiological responses of Bos taurus and Bos indicus cattle to prolonged, continuous heat and humidity. J. Anim. Sci. 84(4): 972-985. doi: 10.2527/2006.844972x

Blaine, K. L., and I. V. Nsahlai. 2011. The effects of shade on performance, carcass classes and behaviour of heat-stressed feedlot cattle at the finisher phase. Trop. Anim. Health Prod. 43(3):609-615. doi:10.1007/s11250-010-9740-x

Bond, T. E., C. F. Kelly, and H. Heitman, Jr. 1958. Improving livestock environment in high temperature areas. J. Hered. 49:75-79.

Bond, T. E., and D. B. Laster. 1975. Influence of shading on production of Midwest feedlot cattle. Trans. ASAE 18(5):957959. doi:10.13031/2013.36717

Boyd, B. M., S. D. Shackelford, K. E. Hales, T. M. Brown-Brandl, L. M. Bremer, M. L. Spangler, T. L. Wheeler, D. A. King, and G. E. Erickson. 2015. Effects of shade and feeding zilpaterol hydrochloride to finishing steers on performance, carcass quality, heat stress, mobility, and body temperature. J. Anim. Sci. 93(12):5801-5811. doi:10.2527/jas.2015-9613

Brosh, A., Y. Aharoni, A. A. Degen, D. Wright, and B. A. Young. 1998. Effects of solar radiation, dietary energy, and time of feeding on thermoregulatory responses and energy balance in cattle in a hot environment. J. Anim. Sci. 76(10): 2671-2677. doi: $10.2527 / 1998.76102671 \mathrm{x}$

Brown-Brandl, T. M., R. A. Eigenberg, J. A. Nienaber, and G. L. Hahn. 2005. Dynamic response indicators of heat stress in shaded and non-shaded feedlot cattle, Part 1: Analyses of indicators. J. Biosyst. Eng. 90:451-462. doi:10.1016/j.biosystemseng.2004.12.006

Brown-Brandl, T. M., R. A. Eigenberg, and J. A. Nienaber. 2006. Heat stress risk factors of feedlot heifers. Livest. Sci. 105(13):57-68. doi:10.1016/j.livsci.2006.04.025

Bruckmaier, R. M., and J. W. Blum. 1992. Responses of calves to treadmill exercise during beta-adrenergic agonist administration. J. Anim. Sci. 70(9): 2809-2821. doi:/1992.7092809x

Chwalibog, A., K. Jensen, and G. Thorbek. 1996. Oxidation of nutrients in bull calves treated with $\beta$-adrenergic agonists. Arch. Anim. Nutr. 49(4):255-261. doi: 10.1080/17450399609381888

Corah, L. 2016. Five ways beef cattle have changed in last 25 years. Feedstuffs Vol. 88.1:42-43.

Eigenberg, R. A., T. M. Brown-Brandl, and J. A. Nienaber. 2009. Effectiveness of Different Shade Materials In: Proceedings, Livestock Environment VIII. TRANS ASABE, Iguassu Falls, Brazil. doi: 10.13031/2013.25587. 
Federation of Animal Science Societies (FASS). 2010. Guide for the care and use of agricultural animals in research and teaching. 3rd ed. FASS, Champaign, IL.

Frese, D. A. 2015. Clinical and diagnostic evaluation of finished cattle exposed to beta adrenergic agonists and physical exertion. PhD. Diss. Kansas State University.

Garrett, W. N., C. F. Kelly, and T. E. Bond. 1962. Total and shaded space allotments for beef feedlots as affected by ration in a high temperature environment. J. Anim. Sci. 21:794-797

Gaughan, J. B., T. L. Mader, and S. M. Holt. 2008. Cooling and feeding strategies to reduce heat load of grain-fed beef cattle in intensive housing. Livest. Sci. 113(2-3):226-233. doi:10.1016/j.livsci.2007.03.014

Gaughan, J. B., S. Bonner, I. Loxton, T. L. Mader, A. Lisle, and R. Lawrence. 2010. Effect of shade on body temperature and performance of feedlot steers. J. Anim. Sci. 88(12):40564067. doi:10.2527/jas.2010-2987

Gaughan, J. B., and T. L. Mader. 2014. Body temperature and respiratory dynamics in un-shaded beef cattle. Int. J. Biometeorol. 58(7):1443-1450. doi:10.1007/s00484-013-0746-8

Hahn, G. L. 1999. Dynamic responses of cattle to thermal heat loads. J. Anim. Sci. 77(Suppl. 2):10-20. doi:10.2527/1997.77suppl_210x

Hubbard, K. G., D. E. Stooksbury, G. L. Hahn, and T. L. Mader. 1999. A climatological perspective on feedlot cattle performance and mortality related to the temperature-humidity index. J. Prod. Agric. 12(4):650-653. doi:10.2134/jpa1999.0650

Johnson, A. K., L. J. Sadler, L. M. Gesing, C. Feuerbach, H. Hill, M. Faga, R. Bailey, K. J. Stalder, and M. J. Ritter. 2010. Effects of facility system design on the stress responses and market losses of market weight pigs during loading and unloading. Prof. Anim. Sci. 26:9-17. doi: 10.15232/S1080-7446(15)30553-2

Loneragan, G. H., D. H. Gould, G. L. Mason, F. B. Garry, G. S. Yost, D. L. Lanza, D. G. Miles, B. W. Hoffman, and L. J. Mills. 2001. Association of 3-methyleneindolenine, a toxic metabolite of 3-methylindole, with acute interstitial pneumonia in feedlot cattle. Am. J. Vet. Res. 62:1525-1530. doi:10.2460/ ajvr.2001.62.1525

Loneragan, G. H., D. U. Thomson, and M. H. Scott. 2014. Increased Mortality in Groups of Cattle Administered the b-Adrenergic Agonists Ractopamine Hydrochloride and Zilpaterol Hydrochloride. PLoS One 9(3):e91177. doi:10.1371/journal. pone.0091177

Mader, T. L., J. M. Dahlquist, G. L. Hahn, and J. B. Gaughan. 1999a. Shade and wind barrier effects on summertime feedlot cattle performance. J. Anim. Sci. 77(8):2065-2072. doi: $10.2527 / 1999.7782065 \mathrm{x}$

Mader, T. L., J. B. Gaughan, and B. A. Young. 1999b. Feedlot Diet Roughage Level for Hereford Cattle Exposed to Excessive Heat Load. Prof. Anim. Sci. 15:53-62. doi: 10.15232/S10807446(15)31724-1

Mader, T. L. 2003. Environmental stress in confined beef cattle. J. Anim. Sci. 81(E.Suppl.2):E110-E119. doi: 10.2527/2003.8114_suppl_2E110x

Mader, T. L., M. S. Davis, and T. Brown-Brandl. 2006. Environmental factors influencing heat stress in feedlot cattle. J. Anim. Sci. 84:712-719. doi: 10.2527/2006.843712x

Mader T. L, and W. M. Kreikemeier. 2006. Effects of growthpromoting agents and season on blood metabolites and body temperature in heifers. J. Anim. Sci. 84: 1030-1037. doi: $10.2527 / 2006.8441030 \mathrm{x}$

Mader, T. L., L. J. Johnson, and J. B. Gaughan. 2010a. A comprehensive index for assessing environmental stress in animals. J. Anim. Sci. 88:2153-2165. doi:10.2527/jas.2009-2586
Mader, T. L., J. B. Gaughan, L. J. Johnson, and G. L. Hahn. 2010b. Tympanic temperature in confined beef cattle exposed to excessive heat load. Int. J. Biometeorol. 54:629-635. doi:10.1007/ s00484-009-0229-0

Mader, T. L. 2014. Bill E. Kunkle Interdisciplinary Beef Symposium: Animal welfare concerns for cattle exposed to adverse environmental conditions. J. Anim. Sci. 92:5319-5324. doi:10.2527/ jas.2014-7950

McKeith, R. O., G. D. Gray, D. S. Hale, C. R. Kerth, D. B. Griffin, J. W. Savell, C. R. Raines, K. E. Belk, D. R. Woerner, J. D. Tatum, J. L. Igo, D. L. VanOverbeke, G. G. Mafi, T. E. Lawrence, R. J. Delmore, Jr., L. M. Christensen, S. D. Shackelford, D. A. King, T. L. Wheeler, L. R. Meadows, and M. E. O'Connor. 2012. National Beef Quality Audit-2011: Harvest-floor assessments of targeted characteristics that affect quality and value of cattle, carcasses, and byproducts. J. Anim. Sci. 90:5135-5142. doi:10.2527/jas.2012-5477

Mersmann, H. J. 1998. Overview of the effects of beta-adrenergic receptor agonists on animal growth including mechanisms of action. J. Anim. Sci. 76:160-172. doi:10.2527/1998.761160x

Mitlöhner, F. M., J. L. Morrow, J. W. Dailey, S. C. Wilson, M. L. Galyean, M. F. Miller, and J. J. McGlone. 2001. Shade and water misting effects on behavior, physiology, performance, and carcass traits of heat-stressed feedlot cattle. J. Anim. Sci. 79: 2327-2335. doi: 10.2527/2001.7992327x

Mitlöhner, F. M., M. L. Galyean, and J. J. McGlone. 2002. Shade effects on performance, carcass traits, physiology, and behavior of heat-stressed feedlot heifers. J. Anim. Sci. 80: 20432050. doi: $10.2527 / 2002.8082043 x$

National Oceanic and Atmospheric Administration (NOAA). Quality Controlled Local Climatological Data. http://www. ncdc.noaa.gov/qclcd/QCLCD (Accessed 3 August 2016.)

National Research Council (NRC). 1981. Effect of environment on nutrient requirements of domestic animals. National Academies Press, Washington, DC.

National Research Council (NRC). 2000. Nutrient requirements of beef cattle. 7th ed. National Academies Press, Washington D.C.

National Research Council (NRC). 2016. Nutrient requirements of beef cattle. 8th ed. National Academies Press, Washington D.C.

Quinn, M. J., C. D. Reinhardt, E. R. Loe, B. E. Depenbusch, M. E. Corrigan, M. L. May, and J. S. Drouillard. 2008. The effects of ractopamine-hydrogen chloride (Optaflexx) on performance, carcass characteristics, and meat quality of finishing feedlot heifers. J. Anim. Sci. 86:902-908. doi:10.2527/jas.2007-0117

Reinhardt, C. D., C. I. Vahl, B. E. Depenbusch, J. P. Hutcheson, and D. U. Thomson. 2014. Feeding zilpaterol hydrochloride is associated with decreased dry matter intake shortly after initiation of feeding dependent on season and previous intake. J. Anim. Sci. 92:4751-4760. doi:10.2527/jas.2014-7562

Robertshaw, D. 2006. Mechanisms for the control of respiratory evaporative heat loss in panting animals. J. Appl. Physiol. 101:664-668. doi:10.1152/japplphysiol.01380.2005

Samuelson, K. L., M. E. Hubbert, M. L. Galyean, and C. A. Löest. 2016. Nutritional recommendations of feedlot consulting nutritionists: The 2015 New Mexico State and Texas Tech University survey. J. Anim. Sci. 94:2648-2663. doi:10.2527/jas.2016-0282

Scanga, J. A., K. E. Belk, J. D. Tatum, T. Grandin, and G. C. Smith. 1997. Factors contributing to the incidence of dark cutting beef and management strategies to reduce the occurrence of dark cutters. J. Anim. Sci. 76(8): 2040-2047. doi: $10.2527 / 1998.7682040 \mathrm{x}$

Simroth, J. C., D. U. Thomson, C. D. Reinhardt, S. J. Bartle, and C. K. Larson. 2016. A survey to describe current cattle feedlot facilities in the United States. Prof. Anim. Sci. (in press). 
St-Pierre, N. R., B. Cobanov, and G. Schnitkey. 2003. Economic losses from heat stress by US livestock industries. J. Dairy Sci. 86:E52-E77. doi:10.3168/jds.S0022-0302(03)74040-5

Strydom, P. E., L. Frylinck, J. L. Montgomery, and F. M. Smith. 2009. The comparison of three b-agonists for growth performance, carcass characteristics and meat quality of feedlot cattle. Meat Sci. 81:557-564. doi:10.1016/j.meatsci.2008.10.011

Sullivan, M. L., A. J. Cawdell-Smith, T. L. Mader, and J. B. Gaughan. 2011. Effect of shade area on performance and welfare of short-fed feedlot cattle. J. Anim. Sci. 89:29112925. doi:10.2527/jas.2010-3152
Taylor, C. R., D. Robertshaw, and R. Hofmann. 1969. Thermal panting: a comparison of wildebeest and zebu cattle. Am. J. Physiol. 217:907-910.

USDA. 2016. USDA National Agricultural Statistics Service. Livestock Slaughter 2015 Summary. Available at: http://usda. mannlib.cornell.edu/usda/nass/LiveSlauSu//2010s/2016/ LiveSlauSu-04-20-2016.pdf (Accessed 2 July 2016).

Valtorta, S. E., P. E. Leva, and M. R. Gallardo. 1997. Evaluation of different shades to improve dairy cattle well-being in Argentina. Int. J. Biometeorol. 41:65-67. doi:10.1007/s004840050055

Woolums, A. R. 2015. Feedlot Acute Interstitial Pneumonia. Vet. Clin. North Am. Food Anim. Pract. 31:381-389. doi:10.1016/j. cvfa.2015.05.010 